NASA

(2)

\title{
Turbulence and Mountain Wave Conditions Observed with an Airborne 2-Micron Lidar
}

Edward H. Teets, Jr.

NASA Dryden Flight Research Center

Edwards, California

\section{Chris Ashburn}

Analytical Services \& Materials, Inc.

Edwards, California

L.J. (Jack) Ehernberger, Retired; and Rodney K. Bogue, Retired NASA Dryden Flight Research Center

Edwards, California

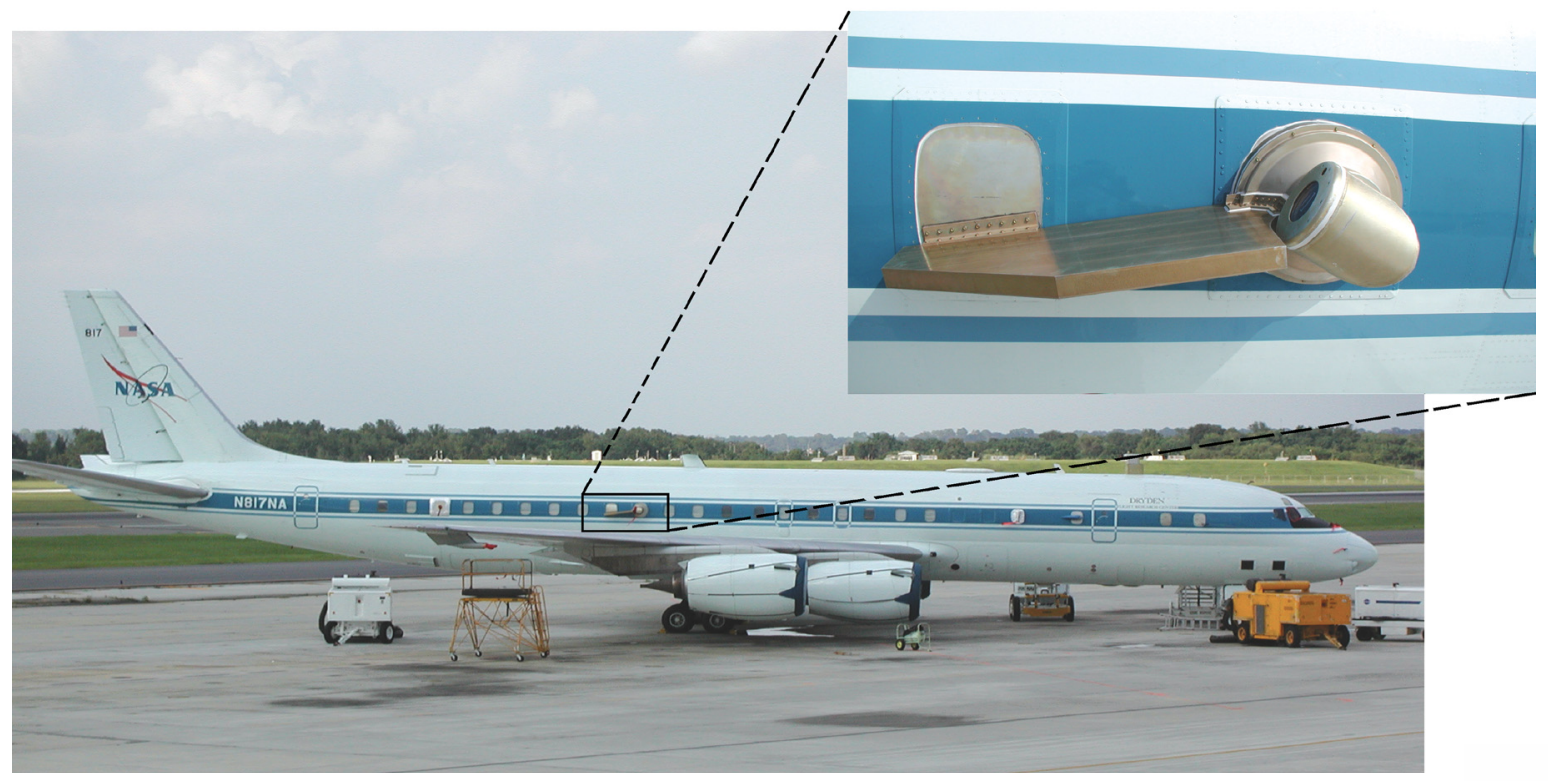

July 2006 


\section{NASA STI Program ... in Profile}

Since its founding, NASA has been dedicated to the advancement of aeronautics and space science. The NASA scientific and technical information (STI) program plays a key part in helping NASA maintain this important role.

The NASA STI program is operated under the auspices of the Agency Chief Information Officer. It collects, organizes, provides for archiving, and disseminates NASA's STI. The NASA STI program provides access to the NASA Aeronautics and Space Database and its public interface, the NASA Technical Report Server, thus providing one of the largest collections of aeronautical and space science STI in the world. Results are published in both non-NASA channels and by NASA in the NASA STI Report Series, which includes the following report types:

- $\quad$ TECHNICAL PUBLICATION. Reports of completed research or a major significant phase of research that present the results of NASA programs and include extensive data or theoretical analysis. Includes compilations of significant scientific and technical data and information deemed to be of continuing reference value. NASA counterpart of peerreviewed formal professional papers but has less stringent limitations on manuscript length and extent of graphic presentations.

- TECHNICAL MEMORANDUM. Scientific and technical findings that are preliminary or of specialized interest, e.g., quick release reports, working papers, and bibliographies that contain minimal annotation. Does not contain extensive analysis.

- $\quad$ CONTRACTOR REPORT. Scientific and technical findings by NASA-sponsored contractors and grantees.
- CONFERENCE PUBLICATION. Collected papers from scientific and technical conferences, symposia, seminars, or other meetings sponsored or cosponsored by NASA.

- SPECIAL PUBLICATION. Scientific, technical, or historical information from NASA programs, projects, and missions, often concerned with subjects having substantial public interest.

- TECHNICAL TRANSLATION. Englishlanguage translations of foreign scientific and technical material pertinent to NASA's mission.

Specialized services also include creating custom thesauri, building customized databases, and organizing and publishing research results.

For more information about the NASA STI program, see the following:

Access the NASA STI program home page at http://www.sti.nasa.gov.

- $\quad$ E-mail your question via the Internet to help@sti.nasa.gov.

- Fax your question to the NASA STI Help Desk at (301) 621-0134.

- $\quad$ Phone the NASA STI Help Desk at (301) 621-0390.

- Write to:

NASA STI Help Desk

NASA Center for AeroSpace Information 7121 Standard Drive

Hanover, MD 21076-1320 
NASA/TM-2006-213682

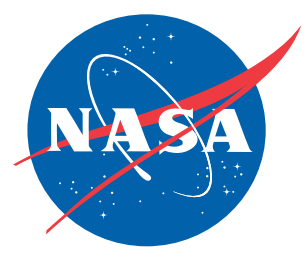

\section{Turbulence and Mountain Wave Conditions Observed with an Airborne 2-Micron Lidar}

Edward H. Teets, Jr.

NASA Dryden Flight Research Center

Edwards, California

Chris Ashburn

Analytical Services \& Materials, Inc.

Edwards, California

L.J. (Jack) Ehernberger, Retired; and Rodney K. Bogue, Retired NASA Dryden Flight Research Center

Edwards, California

National Aeronautics and

Space Administration

Dryden Flight Research Center

Edwards, California 93523-0273

July 2006 
Cover photograph: NASA Dryden Flight Research Center, art number 060133.

\section{NOTICE}

Use of trade names or names of manufacturers in this document does not constitute an official endorsement of such products or manufacturers, either expressed or implied, by the National Aeronautics and Space Administration.

Available from the following:

NASA Center for AeroSpace Information

7121 Standard Drive

Hanover, MD 21076-1320

(301) 621-0390
National Technical Information Service 5285 Port Royal Road

Springfield, VA 22161-2171

(703) 605-6000 


\begin{abstract}
Joint efforts by the National Aeronautics and Space Administration, the Department of Defense, and industry partners are enhancing the capability of airborne wind and turbulence detection. The Airborne Coherent Lidar (light detection and ranging) for Advanced In-Flight Measurements was flown on three series of flights to assess its capability over a range of altitudes, air mass conditions, and gust phenomena. This report describes the observation of mountain waves and turbulence induced by mountain waves over the Tehachapi and Sierra Nevada mountain ranges by lidar on board the NASA Airborne Science DC-8 (McDonnell Douglas Corporation, Long Beach, California) airplane during two flights. The examples in this report compare lidar-predicted mountain waves and wave-induced turbulence to subsequent airplane-measured true airspeed. Airplane acceleration data is presented describing the effects of the wave-induced turbulence on the DC-8 airplane. Highlights of the lidar-predicted airspeed from the two flights show increases of $12 \mathrm{~m} / \mathrm{s}$ at the mountain wave interface and peak-to-peak airspeed changes of $10 \mathrm{~m} / \mathrm{s}$ and $15 \mathrm{~m} / \mathrm{s}$ in a span of $12 \mathrm{~s}$ in moderate turbulence.
\end{abstract}

\title{
NOMENCLATURE
}

ACLAIM

AFB

EDW

g

ICATS

lidar

m

$\mathrm{mJ}$

$\mathrm{m} / \mathrm{s}$

msl

MHV

nsec

NASA

NID

ROS

SNR

TAS

TGS

UTC

WJF
Airborne Coherent Lidar for Advanced In-Flight Measurements

Air Force base

Edwards AFB weather observation site

acceleration of gravity

Information Collection and Transmission System

light detection and ranging

meters

milliJoules

meters per second

mean sea level

Mojave weather observation site

nanoseconds

National Aeronautics and Space Administration

China Lake Naval Weapons Center weather observation site

Rosamond AP156 weather observation site

signal-to-noise ratio

true airspeed

true groundspeed

universal time coordinated

General Wm. J. Fox Airfield weather observation site 
$\begin{array}{ll}\text { X-acceleration } & \text { lateral acceleration } \\ \text { Y-acceleration } & \text { longitudinal acceleration }\end{array}$

\section{INTRODUCTION}

Current in-service commercial and general aviation airplanes lack the capability to detect and mitigate atmospheric turbulence phenomena. Significant turbulence capable of adversely affecting airplane ride comfort and controllability can be generated by convective storms (in visible clouds and in clear air), jet streams (at the confluence of multiple streams and near boundaries), and mountain waves and rotors (upward propagating and vortexes).

To improve detection ahead of the airplane, turbulence and mountain wave observations were made using the Airborne Coherent Lidar (light detection and ranging) for Advanced InFlight Measurements (ACLAIM) system (ref. 1). The ACLAIM was supported by the National Aeronautics and Space Administration (NASA) Aviation Safety Program's Weather Accident Prevention (WxAP) Project, Turbulence Prediction and Warning System (TPAWS) element. The purpose of the ACLAIM program is to determine the viability of forward-looking lidar as a sensor for advanced detection of clear-air turbulence (CAT) and wind shear (ref. 2). One goal of the program was to develop technology that could "see" in front of the airplane leaving sufficient time to warn of impending CAT and to mitigate the effects of CAT on aircraft passengers and crew.

The ACLAIM was flown on the NASA Airborne Science DC-8 (McDonnell Douglas Corporation, Long Beach, California) airplane. The ACLAIM team participated in over 30 DC-8 flights as part of the Convection And Moisture EXperiment 4 (CAMEX-4), Cold Land Processes Field Experiment (CLPX), and the southern California coastal eddies missions. Figure 1 shows the lidar placement on the DC-8 airplane for the year 2003 missions. During these missions, the ACLAIM was operated as a "piggyback" experiment. All flight profiles were driven by the primary mission objectives. On two flight days during the coastal eddies mission the ACLAIM lidar became the primary experiment, allowing the ACLAIM project personnel to determine the flight profiles. The data collected from these two flights is the focus of this report.

Two nearly identical ACLAIM systems were built by Coherent Technologies, Inc. of Lafayette, Colorado: one system for the United States Air Force (USAF) optimized for downward conical scanning, and one system for NASA optimized for forward-looking scanning. The USAF lidar was used in the 1990s by the Airdrop Ballistic Winds (ABW) team at the Air Force Research Laboratory (AFRL) at Wright-Patterson Air Force Base (AFB) to flight-test an innovative windmeasuring instrument that would permit real-time determination of ballistic winds and thereby improve the accuracy of high-altitude airdrops (ref. 3). During the spring 2003 NASA airborne science flight campaigns, the ACLAIM transceiver built for the AFRL was installed on the DC-8 airplane together with the electronics built for the NASA ACLAIM system. Table 1 lists the lidar specifications (ref. 4). 


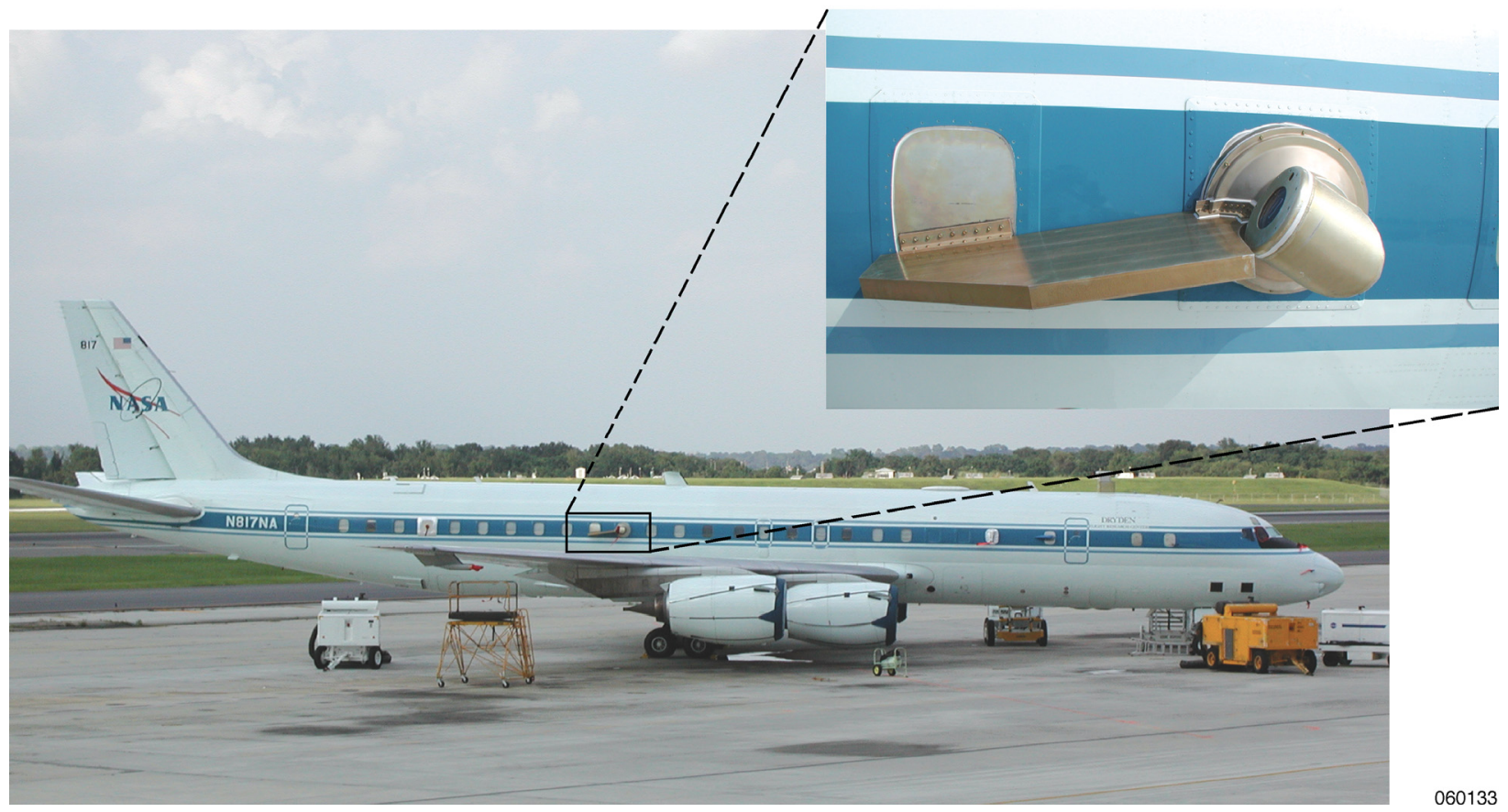

Figure 1. The lidar window assembly on the NASA Airborne Science DC-8 airplane; the rotating periscope is pointing toward the back, in the stowed position (inset).

Table 1. Lidar transceiver specifications (based on autumn 2002 tuneup).

\begin{tabular}{cr}
\hline \hline Parameter & Value \\
\hline Wavelength, $\mathrm{m}$ & 2.0125 \\
Laser pulse energy, mJ (out of telescope) & 9.3 \\
Laser pulse duration, nsec & 650 \\
Pulse repetition frequency, Hz & 100 \\
Beam diameter, cm & 8 \\
Telescope aperture, cm & 10 \\
Focal distance, $\mathrm{km}$ & 2.5 \\
System efficiency, percent & 14 \\
Power, W & 470 \\
\hline
\end{tabular}


The ACLAIM lidar experiment was an independent experiment operated in conjunction with the NASA Airborne Science DC-8 coastal eddies mission. The primary goal of the coastal eddies mission was to use surface in situ measurements and airborne side-looking synthetic aperture radar (AIRSAR) to understand the generation of spiral-shaped "slicks" on the ocean surface that may result from small eddies typically 5 to $10 \mathrm{~km}$ in diameter. These flight missions took place over the Southern California Bight, a region off the California coast between the Santa Barbara Channel and the Gulf of Santa Catalina. These missions required clear skies and at least fairly benign wind conditions to meet the desired objectives. Confined to this restraint, the coastal eddies mission offered little in the way of turbulence. It was, however, during this campaign that the ACLAIM was permitted flight time as the primary experiment. The lidar team decided to seek and observe mountain waves and turbulence of mountain wave rotors as the source of disturbed airflow for the lidar evaluation. Mountain waves are the result of restricted vertical motion in a stable atmosphere caused by the forcing of air over mountain ranges. The vertical motion restriction triggers an oscillating wave motion similar to waves formed by water flowing over rocks in a fast-running stream (ref. 5). Mountain wave rotors are turbulent low-level horizontal vortexes that form downstream in close association with mountain waves (ref. 6). This report details examples of mountain wave and rotor turbulence data collected during these two flights.

\section{DC-8 FIELD OPERATIONS OF APRIL 23 TO APRIL 28, 2003}

The flight of April 23, 2003, dedicated to the lidar team, planned to search for mountain waves being generated off the southern Tehachapi range, notably the Three Sisters. The Three Sisters are three colocated peaks ranging from $6300 \mathrm{ft}$ to $6700 \mathrm{ft}$ in elevation. The flight plan called for a series of flightpaths parallel to the Tehachapi mountain range (perpendicular to the wind field) beginning at an altitude of $4000 \mathrm{ft}$ mean sea level (msl) and progressing upward at 2000-ft intervals to an altitude of $8000 \mathrm{ft} \mathrm{msl}$. Both northwesterly and southeasterly flightpaths were flown at each altitude. A second set of flightpaths were flown perpendicular to the mountain range (parallel to the wind) beginning at an altitude of $8000 \mathrm{ft}$ msl with subsequent 2000 - $\mathrm{ft}$ descents to an altitude of $4000 \mathrm{ft}$ msl. Like the first set of flightpaths, both east and west flightpaths were flown at each altitude. Figure 2(a) shows a closeup view of the flight track used for the flight of April 23, 2003.

The flight plan for the mission of April 28, 2003 allowed the ACLAIM team to "search" for turbulence. With a Pacific storm affecting the west coast of California, the turbulence search was conducted in the Owens Valley, which is located approximately 100 miles north of Edwards Air Force Base (EAFB). The Owens Valley is well-known for producing numerous and monstrous mountain waves (ref. 7). A number of mountain wave research programs have been conducted in the Owens Valley area over the years, two of which were the Sierra Wave project from 1950 to 1955 (ref. 8) and the Terrain-Induced Rotor Experiment (T-REX) in the spring of 2006 (ref. 9). The current absolute altitude world record for a sailplane (49009 ft) was achieved in the same vicinity as that in which the turbulence search was conducted (ref. 10). While the DC-8 airplane was at an altitude of $22000 \mathrm{ft}$ msl, a NASA Dryden Flight Research Center F-18 pilot on a proficiency flight reported turbulence at $15000 \mathrm{ft}$ msl The ACLAIM team then called for the DC-8 airplane to descend to an altitude of $15000 \mathrm{ft}$ msl to investigate the reported turbulence. Once at that altitude, the DC-8 airplane encountered moderate turbulence associated with a mountain wave rotor. Figure 2(b) shows a closeup view of the flight track of the April 28, 2003 turbulence encounter. 


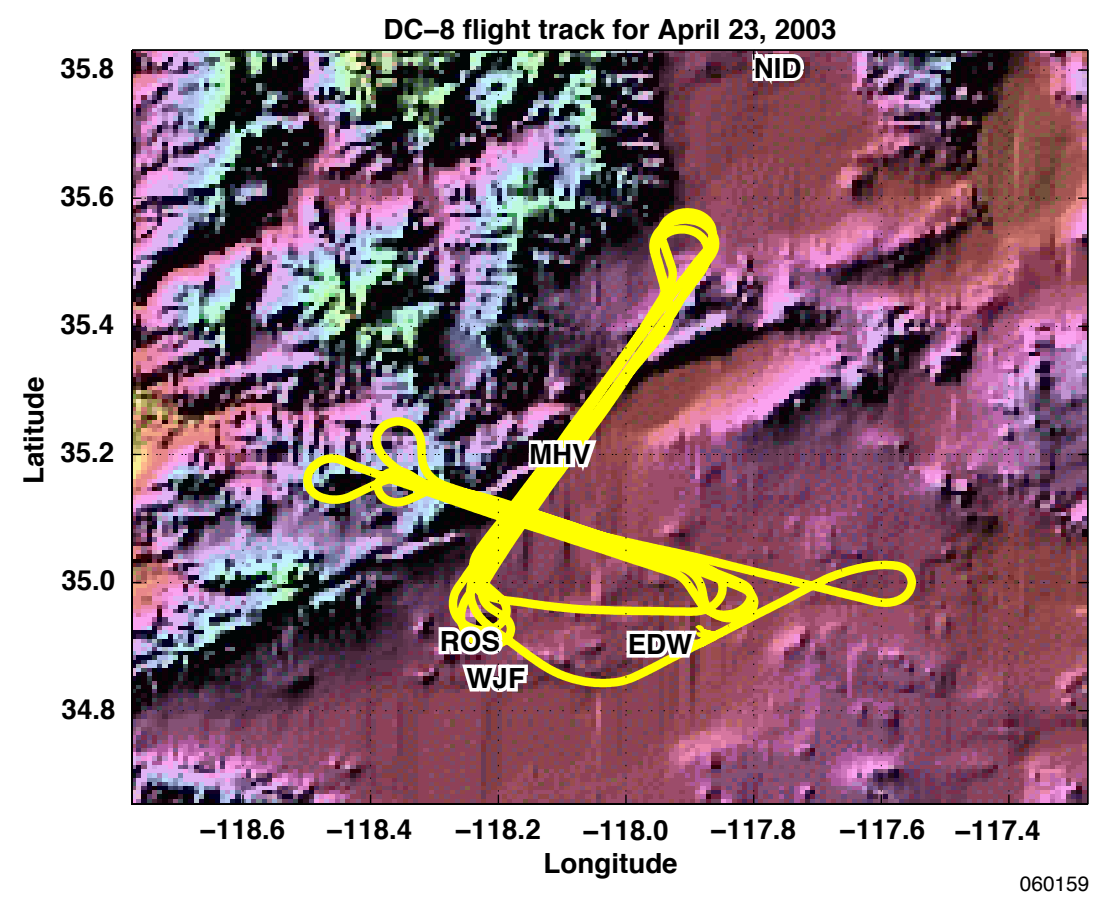

Figure 2(a). Closeup view of the NASA Airborne Science DC-8 flight track of April 23, 2003.

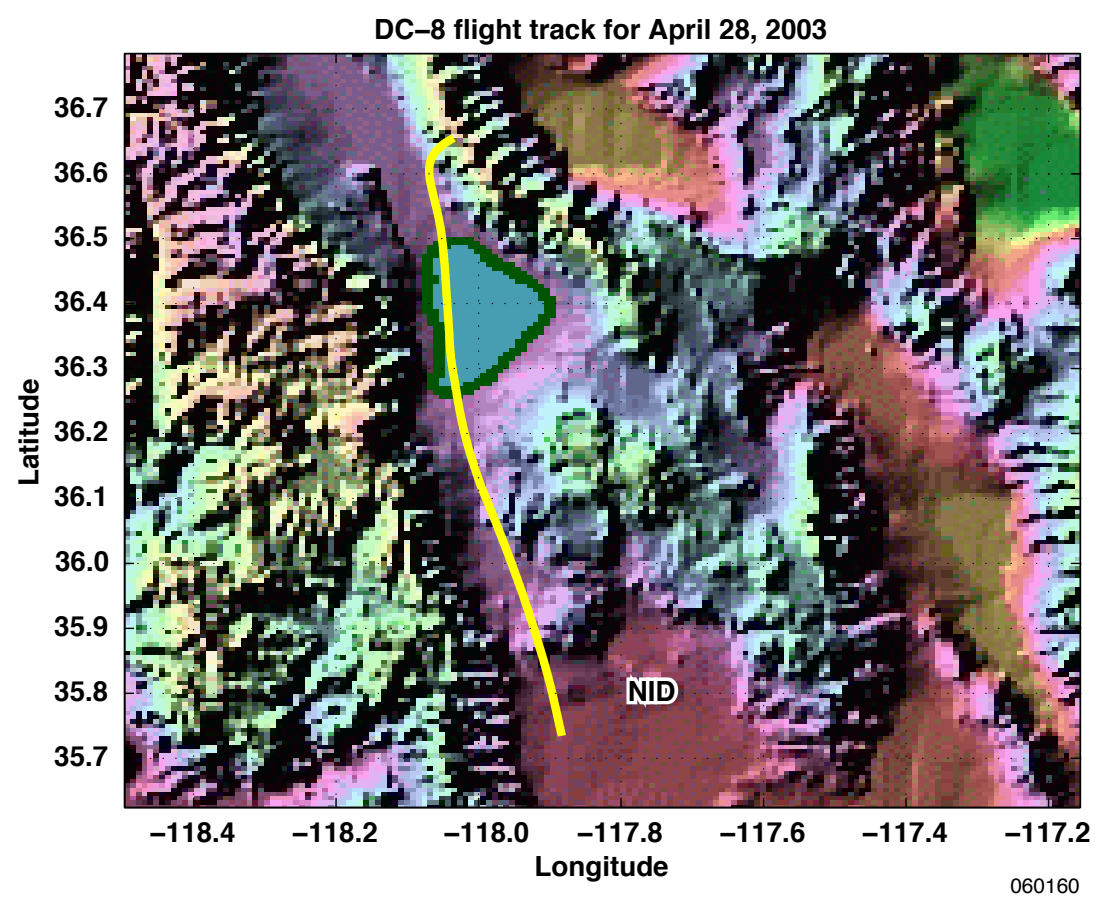

Figure 2(b). Closeup view of the NASA Airborne Science DC-8 flight track of April 28, 2003.

Figure 2. Closeup views of the NASA Airborne Science DC-8 flight tracks of April 23 and 28, 2003. 


\section{DATA RESULTS}

The lidar data display shows radial wind velocity component changes versus distance ahead of the airplane and is compared with the airplane true groundspeed subtracted from the airplane true airspeed (TAS - TGS). In order to perform this comparison, it was necessary to first translate the airplane data into the same coordinates as the lidar display. This was accomplished by using the DC-8 airplane groundspeed and the data sample rate to estimate a distance through space. By translating the DC-8 data versus distance from a given point, the lidar and the airplane TAS - TGS changes can both be plotted as a function of distance ahead of the airplane. With the configuration of the lidar system, this method of comparison will yield significant lidar-to-TAS correlation if: 1) the airplane is not maneuvering (for example, banking or ascending or descending away from the event), 2) the predicted turbulent event is relatively stationary, 3) the lidar signal-to-noise ratio (SNR) was sufficient to produce valid data, 4) the turbulent event is not of such small scale that the DC-8 data acquisition system cannot record it, and 5) the event was somewhat isolated, so that a boundary between perturbed and unperturbed flow can be distinguished.

During the flight of April 23, 2003, the lidar wave signatures were pronounced. Figures 3(a), 3(b), and 3(c) show examples of lidar signals compared with the DC-8 TAS as a function of distance ahead of the airplane. Figure 3(a) shows the lidar signal at 21:32:36 universal time coordinated (UTC) approaching the mountain wave at an altitude of $8000 \mathrm{ft}$ msl with the DC-8 TAS prior to encountering a mountain wave which is located about $5 \mathrm{~km}$ ahead of the airplane. Gaps in the lidar data are a result of SNR being below specified limits and are considered unreliable. The ACLAIM system was built on mid-1990s technology and as a result was underpowered for the long-range detection in clear air that was desired by the project requirements. Figure 3(b), taken $45 \mathrm{~s}$ later, shows a well-developed wave with a 12 meters per second $(\mathrm{m} / \mathrm{s})$ increase in TAS predicted by the lidar. Figure 3(c), taken at 21:37:15 UTC with the DC-8 airplane at an altitude of $6600 \mathrm{ft}$ msl and descending on a southeast heading with a tailwind, presents the mountain wave encounter showing the $12 \mathrm{~m} / \mathrm{s}$ increase in TAS. The lidar signal prediction of a 3-km-long mountain wave and the airplane TAS confirmed this observation. The event was isolated, and the lidar was able to predict the wave structure out to $4 \mathrm{~km}$ (approximately $20 \mathrm{~s}$ ) ahead of the airplane. 


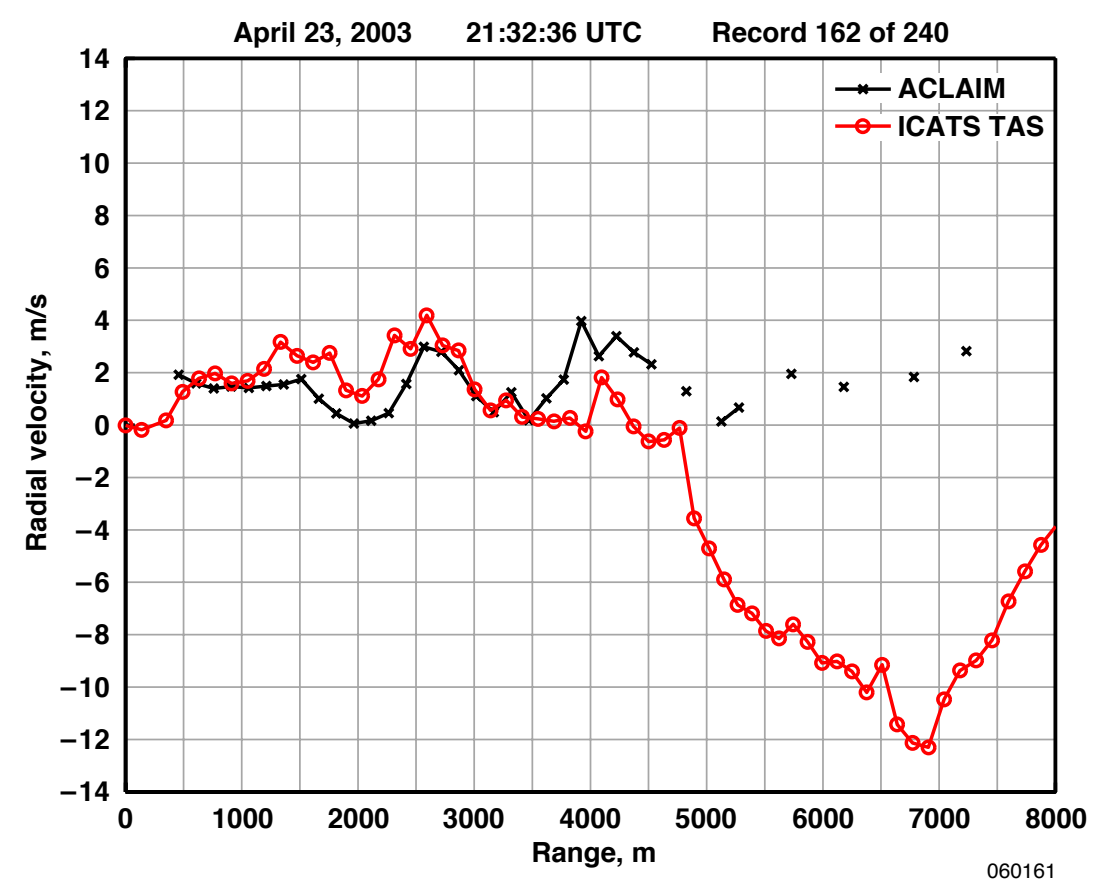

Figure 3(a). The ACLAIM signature approaching a mountain wave.

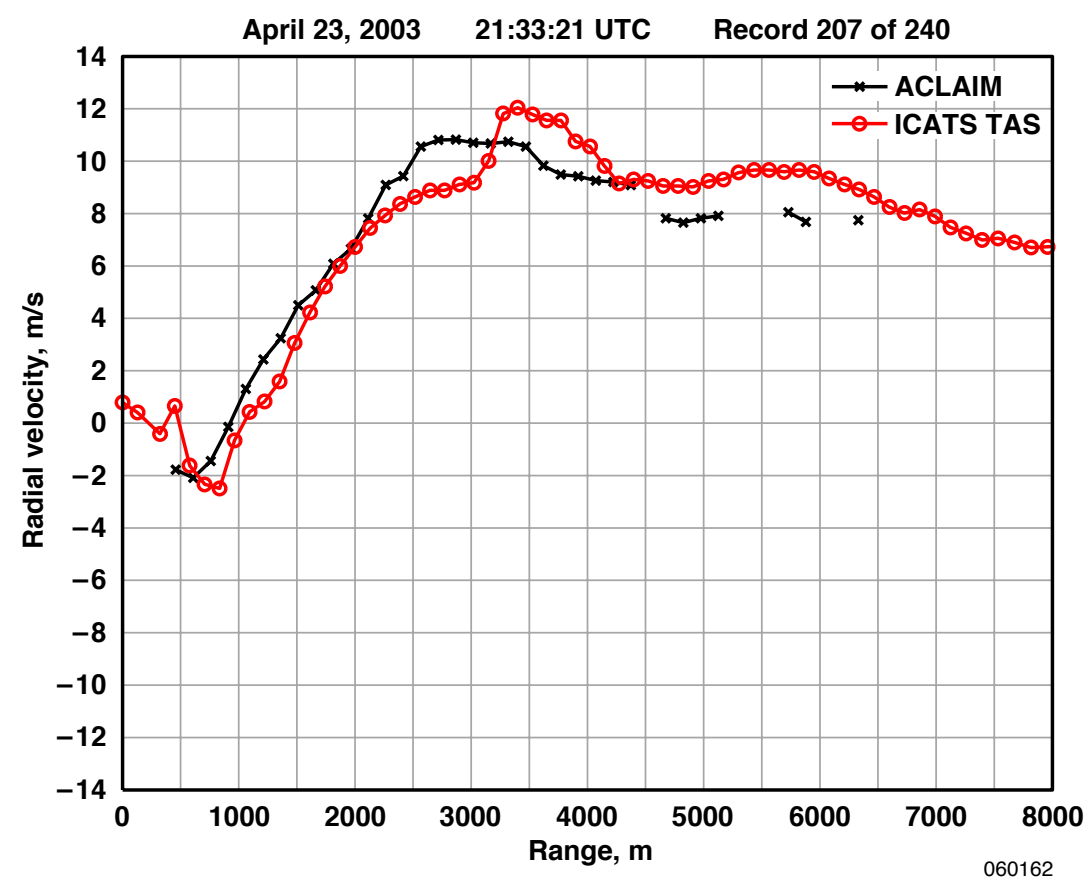

Figure 3(b). The ACLAIM signature just prior to a mountain wave encounter. 


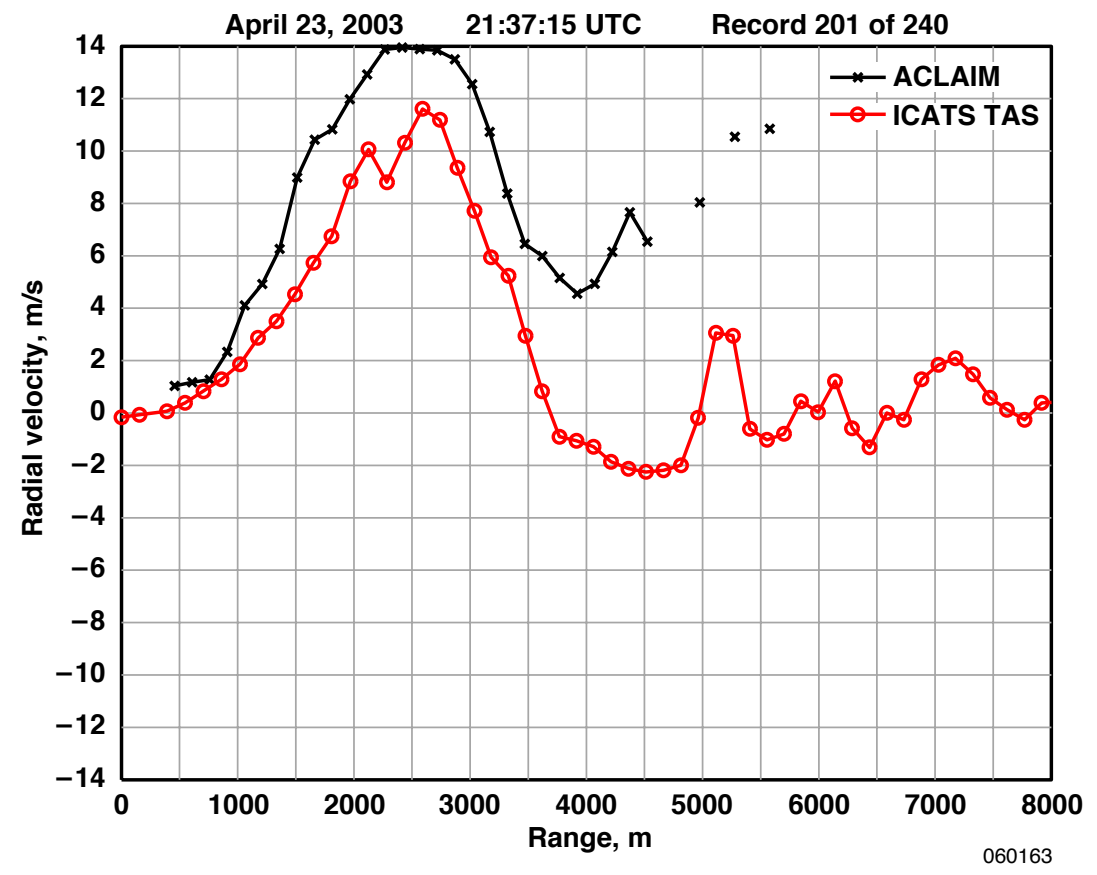

Figure 3(c). The ACLAIM signature of the entire mountain wave.

Figure 3. Examples of lidar signal (+) compared with airplane TAS (o) as a function of distance ahead of the airplane.

The most significant turbulence events from all of the ACLAIM-dedicated flight times occurred during the April 28, 2003 mission. On this mission, near 20:29 UTC the DC-8 airplane was on a north heading at an altitude of $15000 \mathrm{ft}$ msl between the Sierra Nevada and Inyo mountain ranges and perpendicular to the wind field [as shown by the flight track in fig. 2(b)]. A comparison of the lidar prediction to the observed DC-8 TAS during this turbulence encounter is shown in fig. 4. This figure shows the lidar at 20:29:11 UTC with signal returns to $3.5 \mathrm{~km}$ while in turbulence. The $15 \mathrm{~m} / \mathrm{s}$ peak-to-peak ( $1500 \mathrm{~m}$ to $2400 \mathrm{~m}$ ) corresponds to the 1.3 -g excursion shown in fig. 6 . Some signatures of turbulence are observed, but with the prevailing wind being perpendicular to the lidar beam it is very difficult to see the extent of the turbulence signatures parallel to the beam. Figures 5 and 6 show DC-8 acceleration data obtained while flying into and out of the turbulence region. All acceleration data was recorded at 30 samples per second. Evidence of this rotor is observed in figs. 5 and 6 by the abruptness at which the airplane entered and exited the moderate-to-strong turbulence. The first and last $25 \mathrm{~s}$ of data show very little in the way of significant accelerations. Figure 5 shows the lateral and longitudinal accelerations as recorded by the DC- 8 airplane. Figure 6 shows the vertical accelerations obtained during the turbulence encounter. The g-values (normalized to $9.8 \mathrm{~m} / \mathrm{s}^{2}$ ) listed on these figures represent the instantaneous g's as measured by the accelerometers without additional averaging. The 1.3-g vertical acceleration near $193 \mathrm{~s}$ observed in fig. 6 corresponds directly to the lidar signatures in fig. 4. 


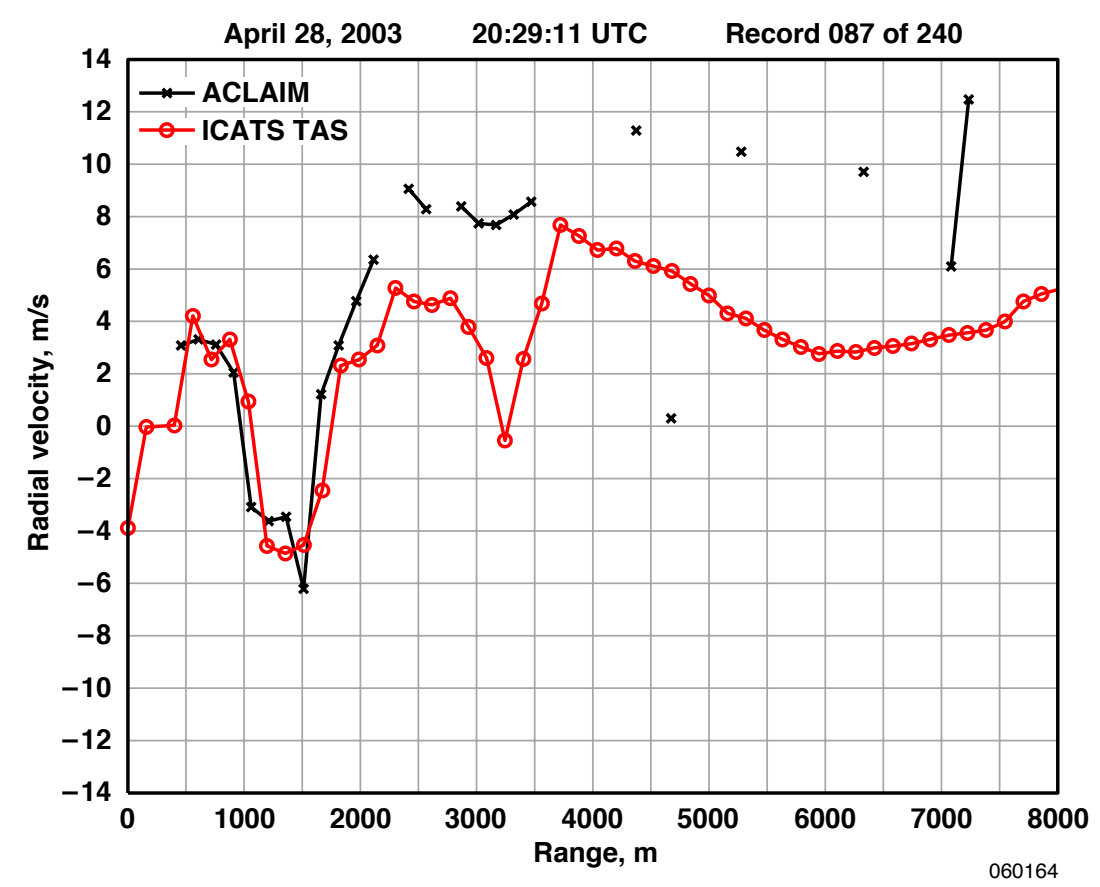

Figure 4. Example of lidar signal (+) compared with airplane TAS (o) as a function of distance ahead of the airplane.

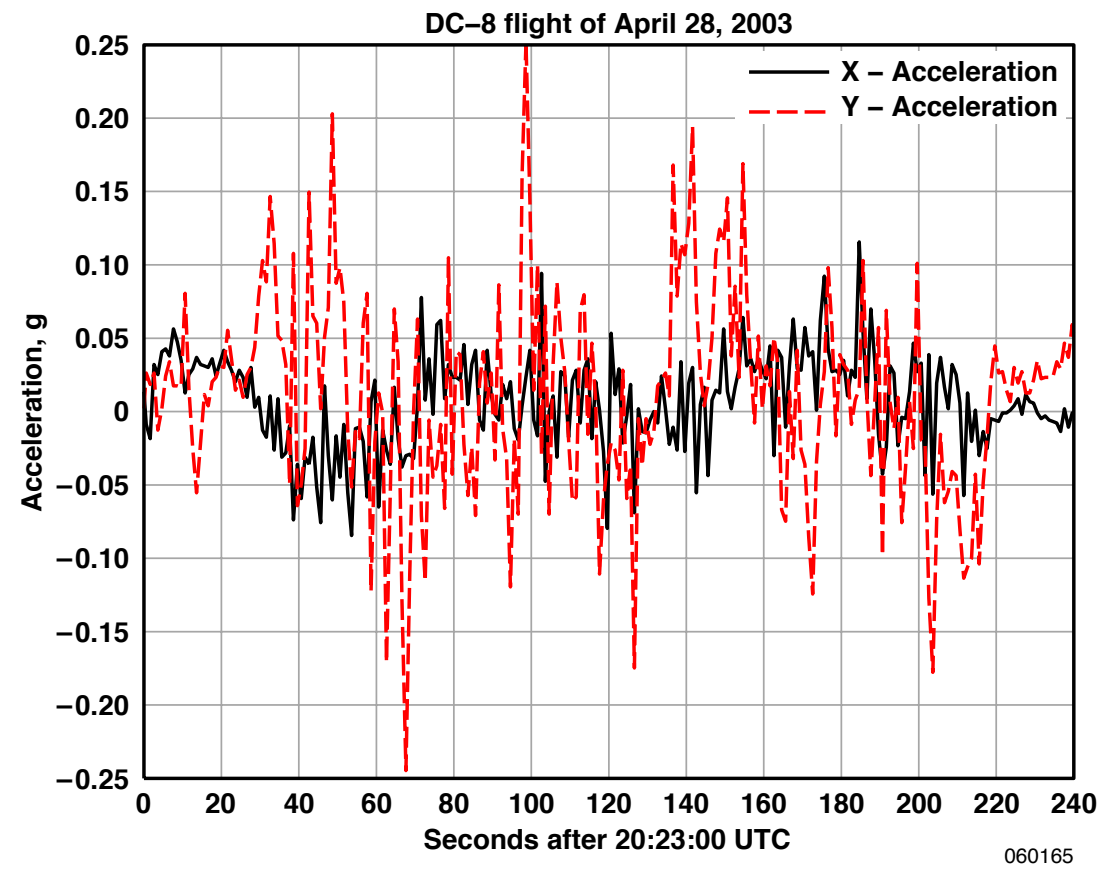

Figure 5. Lateral and longitudinal acceleration data for the April 28, 2003 case; time start $=20: 26: 00$, time stop $=20: 30: 00$. 


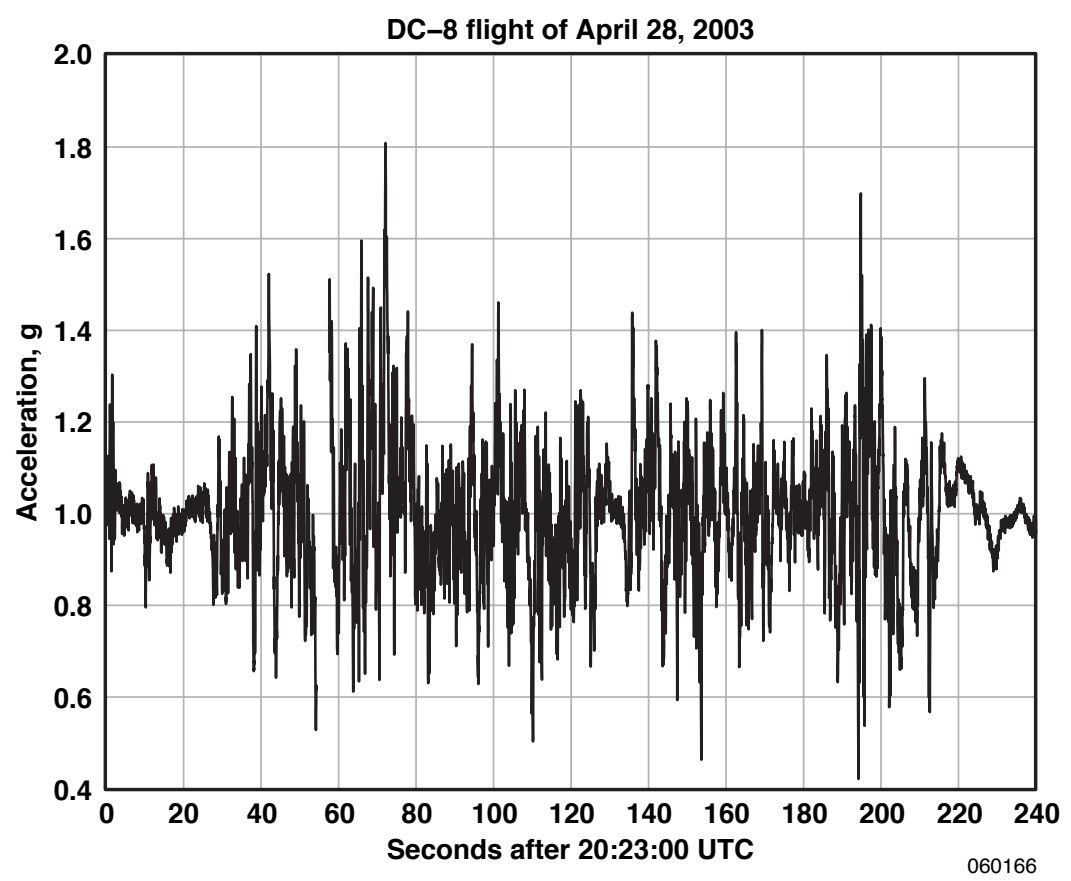

Figure 6. Vertical acceleration data for the April 28, 2003 case; time start $=20: 26: 00$, time stop $=20: 30: 00$.

\section{CONCLUSION}

The Airborne Coherent Lidar (light detection and ranging) for Advanced In-Flight Measurements (ACLAIM) sensor flown on the NASA Airborne Science DC-8 (McDonnell Douglas Corporation, Long Beach, California) airplane detected turbulence and mountain waves at ranges of nearly $4.5 \mathrm{~km}$ at an altitude of $15000 \mathrm{ft}$ and nearly $6.0 \mathrm{~km}$ at an altitude of $6000 \mathrm{ft}$. The longer range of turbulence detection at the lower altitude is a result of the presence of more atmospheric aerosols off of which the lidar energy could reflect. The ACLAIM system detected continuous mountain wave signatures as the DC-8 airplane passed through the wave. Turbulence signatures were detected by the ACLAIM system up to entering the turbulence field, at which point significant maneuvers reduced effective detection. With increasing altitude, detection range was only slightly reduced. Significant increases in lidar power will improve the quality of the returned signal, increasing the range of turbulence detection and thereby increasing the advance time of detection. 


\section{REFERENCES}

1. Soreide, David, Rodney K. Bogue, L.J. Ehernberger, Stephen M. Hannon, and David Bowdle, "Airborne Coherent Lidar for Advanced In-Flight Measurements (ACLAIM) Flight Testing of the Lidar Sensor," prepared for the American Meteorological Society Ninth Conference on Aviation, Range, and Aerospace Meteorology, Orlando, Florida, September 11-15, 2000.

2. Soreide, David, Rodney K. Bogue, L.J. Ehernberger, and Hal Bagley, Coherent Lidar Turbulence Measurement for Gust Load Alleviation, NASA TM-104318, 1996.

3. Carr, John, James Root, Robert Fetner, Michael Salisbury, and Richard Richmond, "Airdrop Ballistic Winds Operationally Capable Lidar," IEEE AES Systems Magazine, May 1999, $31-36$.

4. Bogue, Rodney K., and Henk W. Jentink, Optical Air Flow Measurements in Flight, NASA TP-2004-210735, 2004.

5. Teets, Jr., Edward H., and Elizabeth J. Carter, "Atmospheric Conditions of Stratospheric Mountain Waves: Soaring the Perlan Aircraft to $30 \mathrm{~km}$," preprint 6.10 for the American Meteorological Society 13th Conference on Applied Climatology and 10th Conference on Aviation, Range, and Aerospace Meteorology, Portland, Oregon, May 13-16, 2002.

6. American Meteorological Society, Glossary of Meteorology, http://www.ametsoc.org/MEMB/ onlinemembservices/online_glossary.cfm, accessed July 12, 2006.

7. Whelan, Robert F., Exploring the Monster, Mountain Lee Waves: The Aerial Elevator, Wind Canyon Books, Inc., Niceville, Florida, 2000.

8. Holmboe, Jorgen R., and Harold Klieforth, "Investigation of Mountain Lee Waves and the Air Flow over the Sierra Nevada," Department of Meteorology, University of California Los Angeles, final report, contract number AF 19(604)-728, March 1957.

9. Grubisic, Vanda, and J.P. Kuettner, "Sierra Rotors and the Terrain-Induced Rotor Experiment (T-REX)," American Meteorological Society 11th Conference on Mountain Meteorology and the Annual Mesoscale Alpine Program (MAP), Atlanta, Georgia, June 21, 2004.

10. Fédération Aéronautique Internationale (FAI), The World's Air Sports Federation, Aviation and Space World Records, http://www.fai.org/records, accessed July 12, 2006. 
The public reporting burden for this collection of information is estimated to average 1 hour per response, including the time for reviewing instructions, searching existing

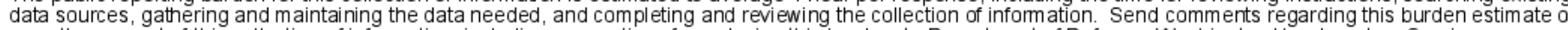
any other aspect of this collection of information, including suggestions for reducing this burden, to Department of Defense, Washington Headquarters Services,

Directorate for Information Operations and Reports (0704-0188), 1215 Jefferson Davis Highway, Suite 1204, Arlington, VA 22202-4302. Respondents should be aw are

that notwithstanding any other provision of law, no person shall be subject to any penalty for failing to comply with a collection of information if it does not display a currently valid OMB control number.

PLEASE DO NOT RETURN YOUR FORMTO THEABOVE ADDRESS
1. REPORT DATE (DD-MM-YYYY)
2. REPORT TYPE
Technical Mem orandum
3. DATES COVERED (From - To) 28-07-2006

4. TITLE AND SUBTITLE

Turbulence and Mountain Wave Conditions Observed with an Airborne

2-Micron Lidar

5b. GRANT NUMBER

5c. PROGRAM ELEMENT NUMBER

\section{AUTHOR(S)}

Teets, Jr., Edward H., Ashbum, Chris, Ehemberger, L.J. (Jack), and Bogue, Rodney K.

5d. PROJECT NUMBER

5e. TASK NUMBER

5f. WORK UNIT NUMBER

WBS:931164.02.01

\section{PERFORMING ORGANIZATION NAME(S) AND ADDRESS(ES)}

8. PERFORMING ORGANIZATION

NASA Dryden Flight Research Center REPORT NUMBER

Edwards, California 93523-0273

H-2654

\section{SPONSORING/MONITORING AGENCY NAME(S) AND ADDRESS(ES)}

National Aeronautics and Space Administration

Washington, DC 20546-0001
10. SPONSORINGIMONITOR'S ACRONYM(S)

NASA

11. SPONSORINGIMONITORING REPORT NUMBER

NASA/TM-2006-213682

\section{DISTRIBUTIONIAVAILABILITY STATEMENT}

Unclassified -- Unlimited

Subject Category 43

Availability: NASA CASI (301) 621-0390

Distribution: Standard

\section{SUPPLEMENTARY NOTES}

Teets, Jr., Ehernberger (Retired), Bogue (Retired), Dryden Flight Research Center; Ashburn, Analytical Services and Materials, Inc.

\section{ABSTRACT}

Joint efforts by the National Aeronautics and Space Administration, the Department of Defense, and industry partners are enhancing the capability of airborne wind and turbulence detection. The Airborne Coherent Lidar (light detection and ranging) for Advanced In-Flight Measurements was flown on three series of flights to assess its capability over a range of altitudes, air mass conditions, and gust phenomena. This report describes the observation of mountain waves and turbulence induced by mountain waves over the Tehachapi and Sierra Nevada mountain ranges by lidar on board the NASA Airborne Science DC-8 (McDonnell Douglas Corporation, Long Beach, California) airplane during two flights. The examples in this report compare lidar-predicted mountain waves and wave-induced turbulence to subsequent airplane-measured true airspeed. Airplane acceleration data is presented describing the effects of the wave-induced turbulence on the DC-8 airplane. Highlights of the lidar-predicted airspeed from the two flights show increases of $12 \mathrm{~m} / \mathrm{s}$ at the mountain wave interface and peak-to-peak airspeed changes of $10 \mathrm{~m} / \mathrm{s}$ and $15 \mathrm{~m} / \mathrm{s}$ in a span of $12 \mathrm{~s}$ in moderate turbulence.

\section{SUBJECT TERMS}

Accelerations, Airborne Science, Airplanes, Aviation safety, Clear-air turbulence, DC-8 airplane, Lidar, Mountain wave, Rotors, Terrain-induced, Vortexes

16. SECURITY CLASSIFICATION OF:

a. REPORT

\section{b. ABSTRACT

b. ABSTRACT

\section{c. THIS PAGE}

\section{LIMITATION OF} ABSTRACT

$\mathrm{U}$

U $\mathrm{U}$

UU

18. NUMBER 1 19a. NAME OF RESPONSIBLE PERSON OF PAGES

STI Help Desk (email: help@sti.nasa.gov) 19b. TELEPHONE NUMBER (Include area code)

16

(301) 621-0390 